\title{
Relationship between Enuresis and Children's Quality of Life
}

\author{
$1^{\text {st }}$ Vanny Fitriana Sari \\ Department of Child Health \\ Faculty of Medicine \\ Universitas Sumatera Utara \\ Medan, Indonesia \\ pipitvanny@gmail.com
}

\author{
$2^{\text {nd }}$ Oke Rina Ramayani \\ Department of Child Health, \\ Faculty of Medicine \\ Universitas Sumatera Utara \\ Medan, Indonesia \\ oke_rina@yahoo.com
}

\author{
$3^{\text {rd }}$ Elmeida Effendy \\ Departement of Psychiatri \\ Faculty of Medicine \\ Universitas Sumatera Utara \\ Medan, Indonesia \\ micipsych@yahoo.com
}

\author{
$4^{\text {th }}$ Munar Lubis \\ Department of Child Health, \\ Faculty of Medicine \\ Universitas Sumatera Utara \\ Medan, Indonesia \\ lubismunar@yahoo.com
}

\begin{abstract}
Enuresis had been reported affecting children in many aspects of life such as physosocial, emotion and school performance which leads to Quality of Life (QoL) impairment. This study aims to assess the relationship between enuresis and children's quality of life. A cross-sectional study was performed in children between the age 5 to 18 years at Muara Batang Gadis, North Sumatera in April 2016. Enuresis was examined using questionnaire International Association for Child and Adolescent Psychiatry and Allied Professions (IACAPAP) and the measurement quality of life using Pediatric Quality of Life Inventory (PedsQL) Generic Core Scales 4.0 version. Data was considered significant if $p<0.05$. There was a significant difference in emotion segment of QoL in 13-18 yo enuretic children compared to healthy children and significant differences in PedsQL total score and emotion segment by age group in enuresis children.
\end{abstract}

\section{Keywords-Enuresis, quality of life, children}

\section{INTRODUCTION}

Enuresis is a common urinary problem in pediatric nephrology unit [1]. Children over 5-year old should be able to control their void at night while they were sleeping. Based on the International Children Continence Society (ICCS), enuresis is defined as episode of children unable to control their voids while they were sleeping after they reached 5 year-old [2]. The prevalence of enuresis varies from epidemiological studies from $3.8 \%$ to $25 \%$ depending on the age of the patient and the terminology used. The prevalence of enuresis in 5 year-old was $15-25 \%$ and decreased with increasing age. Many studies reported that the cause of enuresis was multifactorial factors [3].

Enuresis is also a problem that frequently found in pediatrics psychiatry departement, which mostly affected children's live and their families in many aspects including psychological function [4]. According to population-based studies, it had been reported that enuresis could be the source of shame and influenced children's social life, self image and their daily life within their families and these data are reported to be significant $[5,6]$.
Prolonged enuresis will impact several aspects of the child's life such as psychosocial, emotion, behavior and school performance, which lead to quality of life impairment [5]. The aim of this study is to assess the difference of enuresis children's Quality of Life (QoL) compared to healthy children in $5-18$ year old.

\section{MATERIAL AND METHODS}

This study was a cross sectional study to analyze the difference quality of life between enuresis children and healthy children. This study had been conducted in Singkuang Village, Batang Gadis, Mandailing Natal regency, North Sumatera province in April 2016. The target population were children aged 5-18 years, sample was chosen consecutively. The inclusion criteria is children aged 5 - 18 years who attended school at the time study conducted. The sample selection was conducted at Kindergarten, Primary and Secondary Schools in Singkuang Village. All samples were asked for approval from parents after an explanation about how the examination to be performed. Only those who volunteered were enrolled in the study. Children with cerebral palsy, chronic diseases such as tuberculosis, diabetes mellitus, heart disease, lupus erythematosus, asthma, malignancy which could affect quality of life were excluded from analysis.

The dependent variable in this study is PedsQL score while enuresis as independent variable. Enuresis defined based on ICCS definition which is an episode of children unable to control their voids while they were sleeping after they reached 5 year-old. Healthy child is child who has no physical, mental, emotional and social problems.

Demographic data was collected from samples and they performed physical examination, anthropometry examination, urine analysis and tested for blood sugar level. Enuresis evaluated based on International Association for Child and Adolescent Psychiatry and Allied Professions (IACAPAP) questionnaire and all samples fit the criteria of enuresis assessed their quality of life by using PedsQL 
Generic Core Scales version 4.0. The report includes reports of children and parents in children aged 5-7 years, 8 -12 years, $13-18$ years. The PedsQL scaled between 0 and 100, $100=$ never a problem; $75=$ almost never; $50=$ sometimes; $25=$ almost always; and $0=$ always. Higher value indicates better quality of life.

The collected data was processed and analyzed using statistical computer software. Data was presented as mean and standard deviation. The difference in quality of life between enuresis and healthy children was analyzed using the Mann-Whitney statistical test. While differences in quality of life in enuresis children between age groups using Kruskal Walis test. The results considered to be significant if the $\mathrm{p}$ value $<0.05$.

\section{RESULTS AND DisCUSSION}

The study was conducted in Singkuang Village, Muara Batang Gadis District, Mandailing Natal Regency, North Sumatera province.

TABLE I. SAMPLE CHARACTERISTICS

\begin{tabular}{|c|c|c|}
\hline Characteristics & $\begin{array}{c}\text { Enuresis } \\
(n=54)\end{array}$ & $\begin{array}{c}\text { Healthy } \\
\text { child } \\
(n=54)\end{array}$ \\
\hline \multicolumn{3}{|l|}{ Sex, n (\%) } \\
\hline - Boys & $35(64.8)$ & $34(63.0)$ \\
\hline - Girls & $19(35.2)$ & $20(37.0)$ \\
\hline Age, years (SD) & $9.4(2.51)$ & $10.3(2.42)$ \\
\hline \multicolumn{3}{|l|}{ Age group according PedsQL } \\
\hline - $5-7$ year-old & $13(24.0)$ & $12(22.2)$ \\
\hline - $8-12$ year-old & $33(61.2)$ & $31(57.4)$ \\
\hline - $\quad 13-18$ year-old & $8(14.8)$ & $11(20.4)$ \\
\hline Number of Sibling (SD) & $3.4(2.15)$ & $3.7(1.94)$ \\
\hline \multicolumn{3}{|l|}{ Sibling enuresis history, $\mathrm{n}(\%)$} \\
\hline Yes & $18(33.3)$ & $8(14.8)$ \\
\hline No & $36(66.7)$ & $46(85.2)$ \\
\hline \multicolumn{3}{|l|}{ Paternal enuresis history, $\mathrm{n}(\%)$} \\
\hline Yes & $11(20,4)$ & $4(7,4)$ \\
\hline No & $43(79.6)$ & $50(92.6)$ \\
\hline \multicolumn{3}{|l|}{ Maternal enuresis histrory $\mathrm{n}(\%)$} \\
\hline Yes & $8(14,8)$ & $3(5,6)$ \\
\hline No & $46(85.2)$ & $51(94.4)$ \\
\hline \multicolumn{3}{|l|}{ Paternal education level, n (\%) } \\
\hline Primary school & $42(77.8)$ & $40(74.0)$ \\
\hline Junior High school & $4(7.4)$ & $3(5.6)$ \\
\hline Senior High school & $8(14.8)$ & $11(20.4)$ \\
\hline \multicolumn{3}{|l|}{ Maternal education level, $\mathrm{n}(\%)$} \\
\hline Primary school & $46(85.2)$ & $45(83.3)$ \\
\hline Junior high school & $4(7.4)$ & $4(7.4)$ \\
\hline Senior high school & $1(1.9)$ & $3(5.6)$ \\
\hline Diploma & $1(1.9)$ & $1(1.9)$ \\
\hline Bachelor & $2(3.7)$ & $1(1.9)$ \\
\hline \multicolumn{3}{|l|}{ Father's earning, n (\%) } \\
\hline - <Rp. 500k & $3(5.6)$ & $3(5.6)$ \\
\hline - Rp. 500k- Rp.1.000k & $23(42.6)$ & $26(48.1)$ \\
\hline - Rp. $1.000 \mathrm{k}-$ Rp. $3.000 \mathrm{k}$ & $23(42.6)$ & $20(37.0)$ \\
\hline - >Rp. $3.000 \mathrm{k}$ & $5(9.2)$ & $5(9.3)$ \\
\hline \multicolumn{3}{|l|}{ Mother's earning, $\mathrm{n}(\%)$} \\
\hline - <Rp. 500k & $33(6.1)$ & $39(72.2)$ \\
\hline - Rp. 500k- Rp.1.000k & $13(24.1)$ & $10(18.5)$ \\
\hline - Rp. 1.000k-Rp.3.000k & $5(9.3)$ & $4(7.4)$ \\
\hline - >Rp.3.000k & $3(5.6)$ & $1(1.9)$ \\
\hline
\end{tabular}

The total of patients enrolled in this study were 54 enuresis children and 54 healthy children. Male sex predominates in both groups. The mean age in the enuresis group was 9.4 years with standard deviation 2.51 and in the healthy group 10.3 years with standard deviation 2.42 .

Each group was divided into 3 age groups based on the reporting of the PedsQL questionnaire, 5- 7 years, 8-12 year, and 13 - 18 years. The family history of enuresis was found in the enuresis group consisted of a history of enuresis in siblings were $18(33.3 \%)$, fathers $11(20.4 \%)$ and mothers $8(14.8 \%)$ people. In healthy children group the history of enuresis in siblings were $8(14.8 \%)$ people, fathers $4(7.4 \%)$ people and mothers $3(5.6 \%)$ people. Fathers' incomes in the healthy children group ranged between Rp. 500.000 to Rp.1.000.000, while in enuresis group Rp. 500.0001.000.000 and Rp. 1.000.000 to Rp. 3.000.000 have the same amount. (Table.I)

The result of a quality of life evaluation using PedsQL version 4.0 Generic Core Scales on enuresis groups and healthy children presented in Table 4.2. The statistical test used was Mann-Whitney test. The results of calculations obtained in the age group 5-7 years, and 8-12 years found no difference in quality of life both on the physical, emotional, social, school performance based on child reports and parent reports. While for the age range 13-18 years showed the difference in the quality of life of the emotional function ( $p$ $<0.05$ ) both the parent and child report was significant compared with the healthy child group. While the physical, social, school performance and overall value of PedsQL total did not show significant differences with healthy child groups (Table II).

Table III. shows the differences in PedsQL score in enuresis children by comparing the age-group using Kruskal Wallis test. There was a significant difference in the emotional function of both child and parent reports $(\mathrm{p}<0.05)$. While the total value of PedsQL also shows a significant difference but only in the child report and not on the parent's.

Enuresis is the most common urinary problem of childhood outbreaks [1]. Based on the International Children's Continent Society (ICCS) an enuresis is defined as an episode of the child unable to restrain his or her urine during sleep at night after a 5-year-old child [2]. Prevalence of enuresis varies across countries. Unalacak et al in Turkey say the prevalence of $8.9 \%$ enuresis of which $7.75 \%$ is the primary nocturnal enuresis [7]. In China the prevalence rate is $4.7 \%$ and in Ethiopia is reported at $5 \%$ in small towns and $9 \%$ in large cities $[8,9]$. The prevalence of enuresis in Indonesia was $10.9 \%$ [10].

Some research results reveal that in enuresis children often have psychological and behavioral problems compared with non-enuresis children especially on internalization and externalization issues and this is more prevalent in children with diurnal enuresis. 
TABLE II. PEDSQL SCORES IN ENURESIS AND HEALTHY CHILDREN

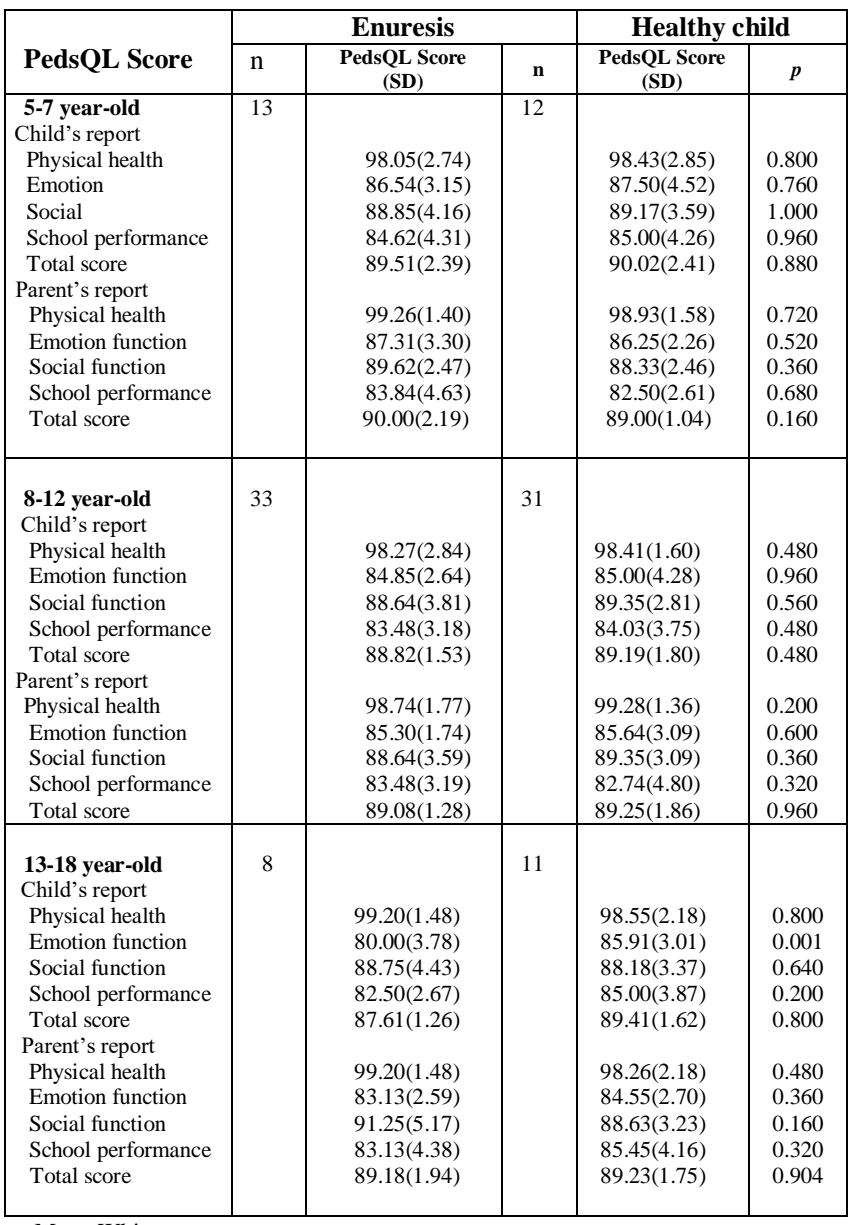

- Mann Whitney test

TABLE III.

PEDSQL SCORES IN ENURESIS BY AGE GROUP

\begin{tabular}{|c|c|c|c|c|c|}
\hline & \multirow[b]{2}{*}{$\mathbf{N}$} & $\begin{array}{l}\text { CHILD'S } \\
\text { REPORT } \\
\end{array}$ & \multirow{2}{*}{$\boldsymbol{P}$} & $\begin{array}{c}\text { PARENT'S } \\
\text { REPORT } \\
\end{array}$ & \multirow{2}{*}{$\boldsymbol{P}$} \\
\hline & & PEDSQL & & PEDSQL & \\
\hline \multicolumn{6}{|l|}{ Physical health } \\
\hline $5-7$ year-old & 13 & $98.05(2.74)$ & & $99.26(1.40)$ & \\
\hline $8-12$ year-old & 33 & $98.27(2.84)$ & 0.672 & $98.74(1.77)$ & 0.598 \\
\hline 13-18 year-old & 8 & $99.20(1.48)$ & & $99.20(1.48)$ & \\
\hline \multicolumn{6}{|l|}{ Emotion function } \\
\hline $5-7$ year-old & 13 & $86.54(3.15)$ & & $87.31(3.30)$ & \\
\hline $8-12$ year-old & 33 & $84.85(2.64)$ & 0.001 & $85.30(1.74)$ & 0.001 \\
\hline 13-18 year-old & 8 & $80.00(3.78)$ & & $83.13(2.59)$ & \\
\hline \multicolumn{6}{|l|}{ Social function } \\
\hline 5-7 year-old & 13 & $88.85(4.16)$ & & $89.62(2.47)$ & \\
\hline $8-12$ year-old & 33 & $88.64(3.81)$ & 0.959 & 88.64(3.59) & 0.100 \\
\hline 13-18 year-old & 8 & $88.75(5.17)$ & & $91.25(5.17)$ & \\
\hline \multicolumn{6}{|l|}{$\begin{array}{l}\text { School } \\
\text { performance }\end{array}$} \\
\hline $5-7$ year-old & 13 & $84.62(4.31)$ & & $83.84(4.63)$ & \\
\hline $8-12$ year-old & 33 & $83.48(3.18)$ & 0.504 & $83.48(3.19)$ & 0.858 \\
\hline 13-18 year-old & 8 & $82.50(2.67)$ & & $83.13(4.38)$ & \\
\hline \multicolumn{6}{|l|}{ PedsQL Total } \\
\hline $5-7$ year-old & 13 & $89.51(2.39)$ & & $90.00(2.19)$ & \\
\hline $8-12$ year-old & 33 & $88.81(1.53)$ & 0.028 & $89.08(1.28)$ & 0.489 \\
\hline 13-18 year-old & 8 & $87.61(1.26)$ & & 89.18(1.94) & \\
\hline
\end{tabular}

Although some studies have assessed the psychopathological aspects of enuresis, it remains unclear whether enuresis children have different personality characteristics than their peers [11, 12, 13]. Most studies have concluded that enuresis has an influence on the quality of life of children in various aspects of life, either emotional aspects, psychosocial or influential on school achievement index $[13,14]$.

This study is a cross-sectional study that assesses the difference in quality of life in enuresis and healthy children, each group involving 54 children. The quality of life analysis in this study used PedsQL Generic Core Scales version 4.0 based on age group 5-7 years, 8-12 years and 13-18 years. Each age group each had a total PedsQL score of 89.51 (2.39), 88.82 (1.53) and 87.61 (1.26), respectively, in accordance with the PedsQL child's values in general. Based on the research of Varni et al in 2002 the total value of child's quality of life in general is $81,38 \pm 15,9[15,16]$.

In this study mostly samples came from low socioeconomic status and parental education levels mostly are primary school graduates. Family enuresis history in this study showed that in enuresis children was found that they have enuresis history in both sibling and their parents higher dan healthy children. In many previous studies reported than psychosocial and environmental factors play an important role as the cause of enuresis, including low socioeconomic status, large number of families, unemployed fathers, densely populated and inadequate housing. The existence of adaptation to new family members as well as parents separation is also known to have an effect on the occurrence of $[17,18]$. Family factors are closely related to the occurrence of enuresis and are thought to have genetically inherited indications. Children whose parents have a history of nearly three quarters of enuresis will experience enuresis $[6,20]$. Children will have $40 \%$ enuresis risk when one parent experiences enuresis and $70 \%$ if both parents experience enuresis. Previous studies have written $32 \%$ of fathers and $23.9 \%$ of mothers with enuresis children had a history of enuresis when they were children $[6,21]$.

The significant difference of PedsQL value of children enuresis and healthy children is statistically only seen in emotional function in 13-18 years age group from child reporting. While the physical, psychosocial and school performance of children and parents report did not show different results as well as the overall value of PedsQL.

In this study also conducted statistical tests comparing PedsQL values in children enuresis between age groups and found that there is a significant difference in the quality of life of the emotional function both in reporting children and parents. As for the total PedsQL value is only meaningful on the reporting result of the child.

In contrast to two previous studies by Kilicoglu et al., And Oktay et al. Both of which also used the generic PedsQL version 4.0 as a measure of the quality of life in enuresis children compared with the control group, there was 
a significant difference in all quality of life functions [4, 14]. Naitoh et al in Japan using KINDL instrument to compare child enuresis with controls found that enuresis same as other chronic diseases that give negative effect to HRQoL [21]. While study conducted by Ertan et al who also use KINDL measuring instrument showed results similar to our results that is not shows a significant difference in the total value of quality of life but has a negative correlation on the confidence subscale [22]. This difference may be due to a smaller sample size than previous studies by Kilicoglu et al with larger samples. While discrepancies in parental reporting results with child reporting may be attributed to parental PedsQL reports that mostly show greater value than child reports. Many of the parents assume that enuresis is a natural thing and will lose itself with age.

The limitation of this study is the small number of samples so that no correlation can be measured between the age of the enuresis children and the quality of life.

\section{CONCLUSION}

There is relationship between enuresis and quality of life of children compared to healthy children, there was a significant difference in the quality of life of emotional function in 13-18 year age group. While the value of PedsQL in enuresis children when compared between age groups found significant differences in total PedsQL value and emotional function.

\section{ACKNOWLEDGMENT}

We thank our beloved staff of pediatric department of Haji Adam Malik Hospital of Universitas Sumatera Utara and we offer our special thanks to Dr. dr. Oke Rina R, Mked.Ped, SpA(K), dr. Elmeida Effendi, Mked.KJ,SpKJ(K) and Prof.dr.H. Munar Lubis, $\operatorname{SpA}(\mathrm{K})$ for their assistance in this research. This research was supported by the Regent of Mandailing Natal District and Principal of SMP Negeri 1 Muara Batang Gadis who have allowed me to do research in the Mandailing Natal area.

\section{REFERENCES}

[1] M. Horowitz and R. Misseri, "Diurnal and nocturnal enuresis," Clinical Pediatric Urology, pp. 819-835, 2007.

[2] O. Ucer, and B. Gumus, "Quantifying subjective assassement of sleep quality, quality of life and depressed mood in children with enuresis," World J Uro, vol 32, pp. 239-243, 2014.

[3] P. Sureshkumar, M. Jones, P.H.Y. Caldwell, and J.C. Craig, "Risk factor for nocturnal enuresis in school-age children," J Urology, vol. 182, pp. 2893-2899, 2009.

[4] A.G. Kilicoglu, C. Mutlu, M.K. Bahali, H. Adaletli, H. Gunes, H.M. Duman, "Impact of enuresis nocturna on health-related quality of life in children and their mothers," Journal of Pediatric Urology, vol. 10, pp. 1261-1266, 2014.

[5] M. Theunis, E.V. Hoecke, S. Paesbrugge, P. Hoebeke, and J.V. Walle, "Self-image and performance in children with nocturnal enuresis," European Urology, vol. 41, pp. 660-667, 2002.

[6] R.J. Butler, "Childhood nocturnal enuresis : developing a conceptual framework," Science Direct, vol. 24, pp. 909-931, 2004.

[7] M. Unalacak, A. Sogul, E. Aktunc, N. Demircan, and R. Altin, "Enuresis noctural prevalence and risk factors among school age children in north west Turkey," European Journal of General Medicine, vol. 3, pp. 21-25, 2004.

[8] J.G. Wen, Q.W. Wang, Y. Chen, J. Wen, and K. Liu, "An epidemiological study of primary nocturnal enuresis in Chinese children and adolescents," European Urology, vol. 49, pp. 1107-1113, 2006.

[9] B. Hagglof, D. Kebede, A. Alem, and M. Desta, "Sociodemographic and psychopathologic correlates of enuresis in urban Ethiopian children," Acta Paediatrica, vol. 96, pp. 556-560, 2007.

[10] W. Trisna and Soetjiningsih, "Prevalence and risk factors of enuresis among kindergarten children in Denpasar," IEE Transl. Sari Pediatri, vol. 10, pp. 151-157, 2008.

[11] B.J. Sadock, and V.A. Sadock, Elimination Disorders. In: Kaplan \& Sadock's Synopsis of Psychiatry-Behavioral Sciences/Clinical Psychiatry. Philadelphia: Lippincot Williams \& Wilkins, 2007.

[12] F.N. Al-Zaben, and M.G. Sehlo, "Punishment for bedwetting is associated with child depression and reduced quality of life," Elsevier, vol. 43, pp. 22-29, 2015.

[13] K. Karnicnik, A. Koren, N. Kos, and M.N. Varda, "Prevalence and quality of life of Slovenian children with primary nocturnal enuresis," International Journal of Nephrology, pp. 2-6, 2012.

[14] U. Oktay, and G. Bilal. "Quantifying subjective assessment of sleep quality, quality of life and depressed mood in children with enuresis," World J Urol, vol.32, pp. 239-243, 2014.

[15] J.W. Varni, T.M. Burwinkle, and M. Seid. "The PedsQL as a pediatric patient-reported outcome: reliability and validity of the PedsQL measurement model in 25.000 children," Exp Rev Pharmacoeconomics Outcomes Res, vol. 5, pp. 705-719, 2005.

[16] I.C. Huang, L.A. Thopmson, Y.Y. Chi, C.A. Knapp, D.A. Revicki, and M. Seid, "The linkage between pediatric quality of life and health conditions: establish in clinically meaningful cut off scores for the PedsQL," Value in health, vol. 12, pp. 773-781, 2009.

[17] P.V. Domelen, M. Kamphuis, J.M. Frank, A. Jeroen, De Wilde, and A. Rijpst, "The short and long term effects of simple behavioral intervensions for nocturnal enuresis in young children : a randomized control trial," J Ped, vol. 154, pp. 626-662, 2009.

[18] M.R. Lawless, and D.H. McElderry, "Nocturnal enuresis: current concepts," Pediatr in Rev, vol. 22, pp. 399-406, 2001.

[19] T.P. Culbert, and G.A. Banez, "Wetting the bed: integrative approaches to nokcturnal enuresis," Pediatrics, vol. 4, pp. 215-220, 2008.

[20] A. Von Gontard, Enuresis. In Rey JM (ed), IACAPAP e-Textbook of Child and Adolescent Mental Health. Geneva: International Association for Child and Adolescent Psychiatry and Allied Professions, 2012.

[21] Y. Naitoh, A. Kawauchi, J. Soh, K. Kamoi, and T. Miki, "Health related quality of life for monosymptomatic enuretic children and their mothers," Jurology, pp. 1910-1914, 2012.

[22] P. Ertan, O. Yilmaz, M. Caglayn, A. Sogut, S. Aslan, and H. Yuksel, "Relationship of sleep quality and quality of life in children with monosymptomatic enuresis," Child Care Health Dev, vol. 34, pp. 469474, 2009. 